\title{
Role of Nerve Growth Factor (NGF) and Its Receptor Tyrosine Kinase A (TrK A) in Egyptian Cirrhotic Patients with Pruritus
}

\author{
Amr Zaghloul*, Hanan Assaf, Reham Ezz, Mohamed Malak, Mahmoud Rezk, Ashraf Askar, \\ Essam El-dinNada
}

Sohag University Hospital, Sohag, Egypt

Email:^amrmoh_80@yahoo.com

How to cite this paper: Zaghloul, A., Assaf, H., Ezz, R., Malak, M., Rezk, M., Askar, A. and El-dinNada, E. (2018) Role of Nerve Growth Factor (NGF) and Its Receptor Tyrosine Kinase A (TrK A) in Egyptian Cirrhotic Patients with Pruritus. Open Journal of Gastroenterology, 8, 317-326. https://doi.org/10.4236/ojgas.2018.89034

Received: July 23, 2018

Accepted: September 23, 2018

Published: September 26, 2018

Copyright (C) 2018 by authors and Scientific Research Publishing Inc. This work is licensed under the Creative Commons Attribution International License (CC BY 4.0).

http://creativecommons.org/licenses/by/4.0/

\section{cc) (i) Open Access}

\begin{abstract}
Background: Pruritus is a distressing symptom of cholestatic, inflammatory, and malignant liver diseases. It is a common symptom in many biliary and cholestatic disorders such as primary biliary cirrhosis (PBC). Several mechanisms are generally accepted as possible explanations to the underlying basis of itch. However, the exact pathophysiology of pruritus in liver diseases remains unclear. The cutaneous and central neurobiology of pruritus is complex and underlies a regulation of variable mechanisms. At present, not all mechanisms including neuromediators and receptors are known. Objective: Our objective is to evaluate whether the expression pattern of NGF and its receptor TrK A has a role in pruritus in a group of Egyptian cirrhotic patients. Patients and Methods: Forty Patients with liver cirrhosis were enrolled in the study depending on clinical evidence of stigmata of chronic liver disease (e.g. jaundice, ascites, palmar erythema, spider naevi, etc.) and ultrasonographic features of liver cirrhosis (e.g. coarse echo texture, shrunken liver, etc.). Patients were divided into two groups. Group (1): included 20 patients cirrhotic patients without pruritus. Group (2): included 20 patients cirrhotic patients with pruritus. A group of age and sex matched healthy twenty volunteers as a control. Results: After evaluation of histopathological using hematoxylin and eosin stained sections (H\&E) was done. There was positive correlation between NGF protein expression and severity of pruritus in cirrhotic patients with pruritus $(\mathrm{r}=0.876$, $\mathrm{p}$ value $\leq 0.001)$. Also there was positive correlation between $\operatorname{TrK}$ A protein expression and severity of pruritus in cirrhotic patients with pruritus $(r=0.44$, $p$ value $\leq 0.05)$. Conclusions: We report, for the first time, role of these proteins (NGF/TrK A) in the mechanism of pruritus in cirrhotic patients and may provide a potential target
\end{abstract}


for new treatment of pruritus in cirrhotic.

\section{Keywords}

Liver Cirrhosis, Itching, Nerve Growth Factor (NGF) and Its Receptor Tyrosine Kinase A (TrK A)

\section{Introduction}

Chronic pruritus or itch (defined as lasting for at least 6 weeks) [1] is a common symptom associated with many dermatological diseases [2], such as eczema orcontact dermatitis, and with psychiatric and neurological disorders [3].

Pruritus is a distressing symptoms of cholestatic, inflammatory, and malignant liver diseases [4]. It is a common symptom in many biliary and cholestatic disorders such as primary biliary cirrhosis (PBC) [5].

Several mechanisms are generally accepted as possible explanations to the underlying basis of itch [6]. However, the exact pathophysiology of pruritus in liver diseases remains unclear [7].

The cutaneous and central neurobiology of pruritus is complex and underlies a regulation of variable mechanisms [8]. At present, not all mechanisms including neuromediators and receptors are known [9].

The common ectodermal origin of nervous system and the skin suggests that growth factors regulating the development and function of neurons are also involved in the control of skin homeostasis and remodeling [10].

Neurotrophins (NTs) belong to a group of functionally and structurally related proteins, the neurotrophic factors' family that were first identified as promoters for neuronal survival [11].

Nerve growth factor (NGF) was the first NT to be discovered during a search for survival factors. Two Brain-derived neurotrophic factor (BDNF) was the second NT to be characterized. It has been identified as a survival factor for several neuronal populations not responsive to NGF. There are four NTs are expressed in mammals: NGF, BDNF, NT-3 NT-4. NT plays a critical role in neurobiological aspect of mental development [10].

Nerve growth factor (NGF) and its receptor tyrosine kinase A (TrK A) were shown to be expressed in healthy human skin where they are involved in sensitization of peripheral neuroreceptors such as the histamine and capsaicin (TRPV1) receptor [12].

\section{Aim of the Study}

The present study aims to explore the expression pattern of NGF and its receptor TrK A in cirrhotic patients with pruritis in comparison to cirrhotic patients without pruritus and to evaluate correlations between tissue levels of measured parameters and severity of the disease. 


\section{Patients and Methods}

This case-control hospital based study was carried out at the Department of Dermatology Venereology and Andrology jointly with Department of Gastroenterology and Tropical Medicine at Sohag University Hospitals Egypt.

\section{Inclusion Criteria}

This study included 40 patients diagnosed with liver cirrhosis depending on clinical evidence of stigmata of chronic liver disease (e.g. jaundice, ascites, palmar erythema, spider naevi, etc.) and ultrasonographic features of liver cirrhosis (e.g. coarse echo texture, shrunken liver, etc.) during the period between January 2018 till June 2018.

Patients were divided into two groups.

Group (1): included 20 patients cirrhotic patients without pruritus.

Group (2): included 20 patients cirrhotic patients with pruritus.

A group of age and sex matched healthy twenty volunteers as a control.

\subsection{Exclusion Criteria}

1) Patients with history of associated endocinal disorders e.g., diabetes mellitus, thyroid disease or chronic renal illness.

2) Patients presented with itchy or non itchy dermatosis.

\subsection{Ethical Consideration}

The study was approved by the Ethics Committee on Research Involving Human Subjects at University of Sohag. All individuals invited were informed in detail about the investigation and voluntarily signed the Informed Consent Form with respect to patient's confidentiality.

\subsection{Methods of the Study}

Each patient included in the study was subjected to:

- Complete history taking and physical examination

Laboratory investigations: total \& differential bilirubin, Aspartate aminotransferase (AST), Alanine aminotransferase (ALT), serum alkaline phosphatase, serum albumin, prothrombin time and concentration, total \& differential bilirubin, hepatitis markers for HBV and HCV, serum creatinine, Haemoglobin level ( $\mathrm{Hb})$.

- Assessment of the severity of liver disease

The functional severity of liver disease was assessed using the Child-Pugh grading system [13].

Child (A) 5 - 6 .

Child (B) 7 - 9.

Child (C) 10 - 15.

- Abdominal ultrasonography

To evaluate liver (size, echogenicity and any focal lesion), portal vein, spleen, 
portosystemic collaterals, and detect ascites.

Dermatological examination: complete dermatological examination was performed including skin, mucous membranes, hair and nails.

The severity of itching was assessed with the 5-D itch score [14]. It is a brief but multidimensional questionnaire. The five dimensions are degree, duration, direction, disability and distribution.

Skin biopsies and immunohistochemical evaluation: punch skin biopsies ( $4 \mathrm{~mm}$ ) each were obtained from each included patient and the control fixation was done using $10 \%$ neutral phosphate-buffered formalin for 24 hours. The formalin fixed-paraffin embedded tissues were processed for routine histology (Hematoxylin and eosin stains) and special (Giemsa stain) as well as immunohistochemical stains at the Department of Pathology.

\section{Statistical Analysis}

Data was analyzed using SPSS computer program version 22.0.

Quantitative data was expressed as means \pm standard deviation, median and range. Qualitative data was expressed as number and percentage. The data were tested for normality using Shapiro-Wilk test. The non parametric Man-Whitney test, Kruskal-Wallis test and Spearman's correlation were used for data which wasn't normally distributed.

One-Way ANOVA test and Pearson's correlation were used for normally distributed data. Chi-Square test was used for comparison between qualitative variables. A 5\% level was chosen as a level of significance in all statistical tests used in the study.

\section{Results}

The study included 40 patients with mean age $(52 \pm 9.1)$ were divided into two groups; cirrhotic patients with pruritus $(\mathrm{N}=20)$, cirrhotic patients without pruritus $(\mathrm{N}=20)$ as well as 20 age and sex matched healthy volunteers as a control group.

The main aetiology of liver cirrhosis was HCV infection in $50 \%$ of cases.

There were no significant differences between the two groups as regard age and gender as shown in Table 1.

Table 2 showed no significant differences between the two groups as regard the clinical and the laboratory parameters.

The itching was severe among patients with HCV infection as shown in Table 3.

There was positive correlation between NGF protein expression and severity of pruritus in cirrhotic patients with pruritus $(r=0.876, p$ value $\leq 0.001)$ as shown in Figure 1.

There was positive correlation between $\operatorname{TrK}$ A protein expression and severity of pruritus in cirrhotic patients with pruritus $(r=0.44$, $p$ value $\leq 0.05)$ as shown in Figure 2. 
Table 1. Demographic characteristics are summarized in Table 1 and there were no significant differences between the two groups as regards any of these parameters.

\begin{tabular}{cccc}
\hline Parameter & $\begin{array}{c}\text { Group 1 } \\
\text { (without pruritus) } \\
(\mathrm{N}=20)\end{array}$ & $\begin{array}{c}\text { Group 2 } \\
(\text { with pruritus }) \\
(\mathrm{N}=20)\end{array}$ & p-value \\
\hline Age & & & $0.234^{*}$ \\
Mean \pm S.D. & $55.7 \pm 5.3$ & $52.7 \pm 9.1$ & \\
Median (Range) & $55(47-67)$ & $55(35-67)$ & $0.766^{* *}$ \\
Gender & & & \\
Males & $11(55 \%)$ & $9(45 \%)$ & $11(55 \%)$ \\
Females & $9(45 \%)$ & & \\
\hline
\end{tabular}

${ }^{*} \mathrm{p}$-value was calculated by Kruskal Wallis test; ${ }^{* *} \mathrm{p}$-value was calculated by Chi-Square test.

Table 2. Clinical and laboratory characteristics of studied population.

\begin{tabular}{|c|c|}
\hline Characteristics & \\
\hline \multicolumn{2}{|l|}{ Ascites } \\
\hline No & $19(47.5 \%)$ \\
\hline Yes & $21(52.5 \%)$ \\
\hline \multicolumn{2}{|l|}{ Lower limb edema } \\
\hline No & $29(72.5 \%)$ \\
\hline Yes & $11(27.5 \%)$ \\
\hline \multicolumn{2}{|l|}{ Jaundice } \\
\hline No & $25(62.5 \%)$ \\
\hline Yes & $15(37.5 \%)$ \\
\hline \multicolumn{2}{|c|}{ Aetiology of liver cirrhosis } \\
\hline $\mathrm{HBV}$ & $10(25 \%)$ \\
\hline $\mathrm{HCV}$ & $21(52.5 \%)$ \\
\hline Mixed & $6(15 \%)$ \\
\hline Unknown & $3(7.5 \%)$ \\
\hline \multicolumn{2}{|l|}{$\operatorname{ALT}(\mathrm{IU} / \mathrm{L})$} \\
\hline Mean \pm S.D. & $32.6 \pm 5.8$ \\
\hline Median (Range) & $30.5(24-45)$ \\
\hline \multicolumn{2}{|l|}{ Bilirubin (mg/dl) } \\
\hline Mean \pm S.D. & $2.4 \pm 1.2$ \\
\hline Median (Range) & $2.4(1-6)$ \\
\hline \multicolumn{2}{|l|}{ Albumin (mg/dl) } \\
\hline Mean \pm S.D. & $3.3 \pm 0.7$ \\
\hline Median (Range) & $3.3(2-4.5)$ \\
\hline \multicolumn{2}{|l|}{ Prothrombin } \\
\hline Mean \pm S.D. & $4.7 \pm 1.2$ \\
\hline Median (Range) & $4.6(3-7)$ \\
\hline
\end{tabular}

\section{Histopathological Findings}

Evaluation of histopathological using hematoxylin and eosin stained sections (H\&E) was done and compared among the studied three groups as shown in Table 4. In the skin biopsy specimens of the cirrhotic patients with pruritus we found several histological changes including: epidermal hyperplasia (acanthosis), 
Table 3. Comparison between group 1 and group 2 regarding clinical and laboratory data.

\begin{tabular}{|c|c|c|c|}
\hline Parameter & $\begin{array}{c}\text { Group } 1 \\
\text { (without pruritus) } \\
(\mathrm{N}=20)\end{array}$ & $\begin{array}{c}\text { Group } 2 \\
\text { (with pruritus) } \\
(\mathrm{N}=20)\end{array}$ & $\mathrm{p}$-value \\
\hline \multicolumn{4}{|l|}{ Ascites } \\
\hline No & $7(35 \%)$ & $12(60 \%)$ & $0.113^{*}$ \\
\hline Yes & $13(65 \%)$ & $8(40 \%)$ & \\
\hline \multicolumn{4}{|l|}{ Lower limb edema } \\
\hline No & $14(70 \%)$ & $15(75 \%)$ & $0.723^{*}$ \\
\hline Yes & $6(30 \%)$ & $5(25 \%)$ & \\
\hline \multicolumn{4}{|l|}{ Jaundice } \\
\hline No & $12(60 \%)$ & $13(65 \%)$ & $0.744^{\star}$ \\
\hline Yes & $8(40 \%)$ & $7(35 \%)$ & \\
\hline \multicolumn{4}{|l|}{ ALT (IU/L) } \\
\hline Mean \pm S.D. & $31.9 \pm 5.04$ & $33.4 \pm 6.6$ & $0.673^{* *}$ \\
\hline Median (Range) & $30(25-45)$ & $31(24-45)$ & \\
\hline \multicolumn{4}{|l|}{ Bilirubin (mg/dl) } \\
\hline Mean \pm S.D. & $2.6 \pm 1.3$ & $2.2 \pm 1.08$ & $0.481^{* *}$ \\
\hline Median (Range) & $2.5(1-6)$ & $1.9(1-4.1)$ & \\
\hline \multicolumn{4}{|l|}{ Albumin (mg/dl) } \\
\hline Mean \pm S.D. & $3.2 \pm 0.7$ & $3.4 \pm 0.7$ & $0.231^{* *}$ \\
\hline Median (Range) & $3.1(2-4.5)$ & $3.6(2.1-4.5)$ & \\
\hline \multicolumn{4}{|l|}{ Prothrombin } \\
\hline Mean \pm S.D. & $4.8 \pm 1.3$ & $4.5 \pm 1.3$ & $0.341^{* *}$ \\
\hline Median (Range) & $4.8(3-7)$ & $4.1(3-6.8)$ & \\
\hline \multicolumn{4}{|c|}{ Stage of liver cirrhosis } \\
\hline Stage A & $6(30 \%)$ & $10(50 \%)$ & $0125 * x$ \\
\hline Stage B & $9(45 \%)$ & $6(30 \%)$ & $0.425^{\star \star}$ \\
\hline Stage C & $5(25 \%)$ & $4(20 \%)$ & \\
\hline
\end{tabular}

${ }^{*} \mathrm{p}$-value was calculated by Chi-Square test; ${ }^{* *} \mathrm{p}$-value was calculated by Mann-Whitney U Test.

Table 4. Relation between severity score of pruritus and cause of cirrhosis.

\begin{tabular}{cccccc}
\hline Severity score & $\begin{array}{c}\text { HBV } \\
(\mathrm{N}=4)\end{array}$ & $\begin{array}{c}\text { HCV } \\
(\mathrm{N}=10)\end{array}$ & $\begin{array}{c}\text { Mixed } \\
(\mathrm{N}=3)\end{array}$ & $\begin{array}{c}\text { Unknown } \\
(\mathrm{N}=3)\end{array}$ & p-value \\
\hline Mean \pm S.D. & $10 \pm 1.2$ & $19.3 \pm 3.1$ & $12.7 \pm 2.5$ & $11.7 \pm 2.5$ & $0.003^{*}$ \\
Median (Range) & $10(9-11)$ & $19.5(14-24)$ & $13(10-15)$ & $2(9-14)$ & \\
\hline
\end{tabular}

${ }^{*}$ p-value was calculated by Kruskal Wallis test. *Statistically significant.

vascular ectasia (dilated dermal blood vessels), hypertrophied dermal nerve endings, leucocytoclasia (swelling of the endothelial cell lining of the blood vessels without fibrinoid necrosis, or extravasation of red blood cells) and lymphocytic vasculopathy. Evaluation of mast cell count in Gimesa stained skin sections revealed an increased numbers of these cells in the group of cirrhotic patients with pruritus $(\mathrm{N}=5-10)$. The cells noted in perivascular, perineural and interstitial distribution (between collagen bundles) (Figure 3). 




Figure 1. Correlation between severity score and NGF expression in patients with pruritus.

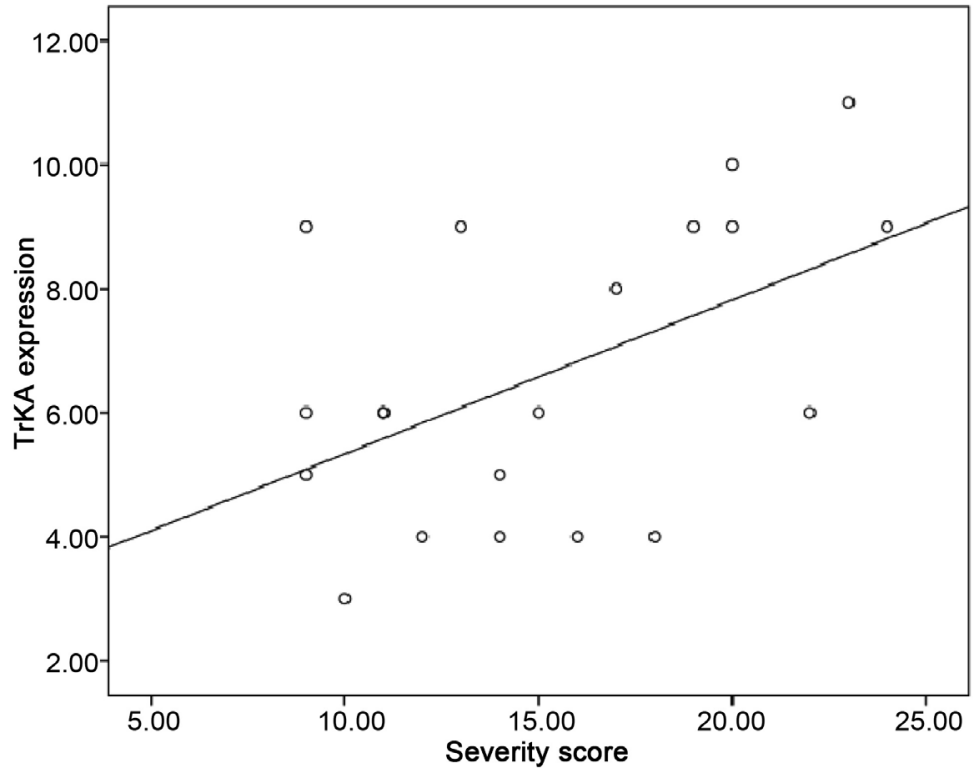

Figure 2. Correlation between severity score and TrK A expression in patients with pruritus.

\section{Discussion}

Pruritus is a common symptom in hepatobiliary disorders, particularly in those related to cholestasis [15]. Its prevalence is variable among liver diseases, ranging from $5 \%$ in chronic hepatitis $\mathrm{C}$ virus infection to $70 \%$ in primary biliary cirrhosis [16].

Despite the major advances in the last 15 years in the study of pruritus it remains unclear how peripheral and central mechanisms take place, increased production and release of cytokines, neuropeptides and neurotrophins possibly 

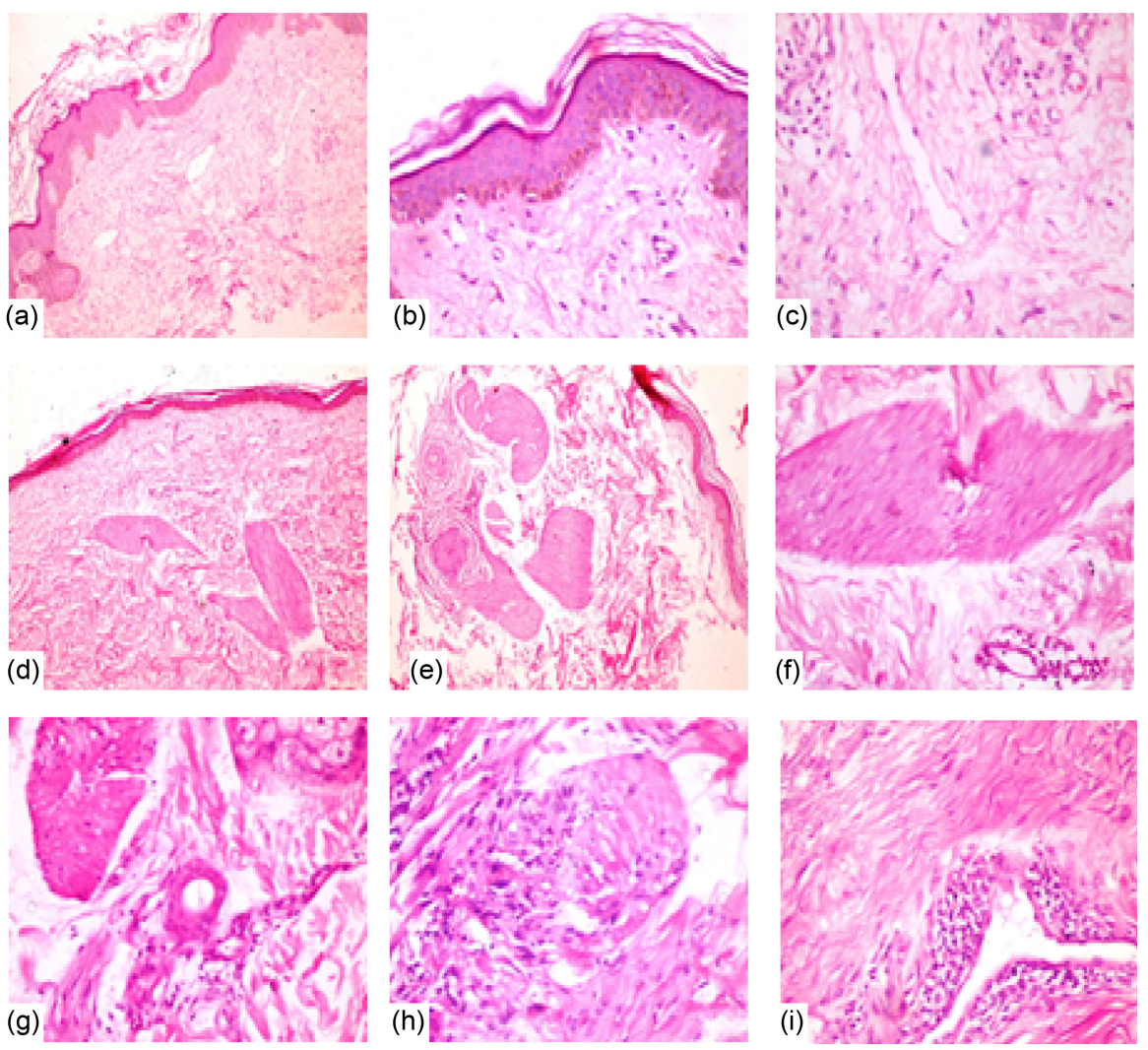

Figure 3. H\&E stained tissue sections showing histological differences between cirrhotic patients with and without pruritus. (a)-(b): Non-pruritus skin ((a) 100×) ((b) 200×). (c)-(i): Pruritus skin with: vascular ectasia ((c) $(400 \times))$, hypertrophied Nerves (d)-(f) ((d) $100 \times$, (e) $200 \times$, (f) 400×), inflammatory cells around the nerves ((h) 400×) and lymphocytic vasculopathy ((i) $400 \times)$.

lead to exacerbation of pruritus [17].

To the best of our knowledge, there were no previous studies that investigated the expression pattern of NGF and its receptor TrK A in cirrhotic patients with pruritus.

We carried out this investigation using immunohistochemical technique to fill this existing gap in literature and to test our hypothesis.

We found also increased numbers of mast cells which have perivascular, perineural and interstitial distribution and bile acids are known to be potent activators of mast cells causing histamine excretion that might also constitute the reason for itch [18].

In the current study, the expression pattern of NGF protein in the skin of cirrhotic patients with pruritus in comparison to non-pruritus and normal healthy skins.was higher in both the epidermis and dermal adnexal structures in cirrhotic patients with pruritus and this agree with Dou et al. [9] who reported that there were higher levels of NGF in the keratinocytes of the epidermal basal and spinal layers, and more in dermal infiltrating inflammatory cells in the early atopic dermatitis lesion, compared to the controls.

The study also demonstrate that there is a relation between severity of pruritus 
and HCV as a cause of cirrhosis, Desphande et al. [19] found that the mechanisms of $\mathrm{HCV}$-associated pruritus are attributed to $\mathrm{HCV}$-induced cholestasis and the induction of interferon-stimulated genes as a result of viral overload.

The elevated production of cytokines (e.g., IL-8) and chemokines during the course of cholestatic HCV is expected to be the main mediators for the induction of HCV-associated pruritus [20].

In conclusion, Our novel findings suggest a pathophysiological role of these proteins (NGF/TrK A) in the mechanism of pruritus in cirrhotic patients and may provide a potential target for new treatment of pruritus in cirrhotic patients.

\section{Conflicts of Interest}

The authors declare no conflicts of interest regarding the publication of this paper.

\section{References}

[1] Ständer, S., Weisshaar, E., Mettang, T., Szepietowski, J.C., Carstens, E., Ikoma, A., et al. (2007) Clinical Classification of Itch: A Position Paper of the International Forum for the Study of Itch. Acta Dermato-Venereologica, 87, 291-294. https://doi.org/10.2340/00015555-0305

[2] Sommer, F., Hensen, P., böckenholt, B., Metze, D., Luger, T.A. and Ständer, S. (2007) Underlying Diseases and, Co-Factors in Patients with Severe Chronic Pruritus: A 3-Year Retrospective Study. Acta Dermato-Venereologica, 87, 510-516. https://doi.org/10.2340/00015555-0320

[3] Weisshaar, E., Apfelbacher, C., Jager, G., Zimmermann, E., Bruckner, T., Diepgen, T.L. and Gollnick, H. (2006) Pruritus as a Leadingsymptom: Clinical Characteristics and Quality of Life Ingerman and Ugandan Patients. British Journal of Dermatolo$g y$, 155, 957-964. https://doi.org/10.1111/j.1365-2133.2006.07430.x

[4] Bergasa, N.V. (2011) The Itch of Liver Disease. Seminars in Cutaneous Medicine and Surgery, 30, 8-93. https://doi.org/10.1016/j.sder.2011.04.009

[5] Zein, C.O. and Lindor, K.D. (2010) Latest and Emerging Therapies for Primary Biliary Cirrhosis and Primary Sclerosing Cholangitis. Current Gastroenterology Reports, 12, 13-22. https://doi.org/10.1007/s11894-009-0079-2

[6] Patel, K.N. and Dong, X. (2011) Itch: Cells, Molecules, and Circuits. ACS Chemical Neuroscience, 2, 17-25.

[7] Oude Elferink, R.P., Kremer, A.E., Martens, J.J. and Beuers, U.H. (2011) The Molecular Mechanism of Cholestatic Pruritus. Digestive Diseases, 29, 66-71. https://doi.org/10.1159/000324131

[8] Nockher, W.A. and Renz, H. (2006) Neurotrophins in Allergic Diseases: From Neuronal Growth Factor to Intercellular Signaling Molecules. Journal of Allergy and Clinical Immunology, 117, 583-589. https://doi.org/10.1016/j.jaci.2005.11.049

[9] Dou, Y., Hagstromer, L. and Emtestam, L. (2006) Increased Nerve Growth Factor and Its Receptors in Atopic Dermatitis: An Immunohistochemical Study. Archives of Dermatological Research, 298, 31-37. https://doi.org/10.1007/s00403-006-0657-1

[10] Botchkarev, V., Peters, E. and Paus, R. (2004) Epithelial Growth Control by Neurotrophins: Leads and Lessons from the Hair Follicle. Progress in Brain Research, 146, 
493-513. https://doi.org/10.1016/S0079-6123(03)46031-7

[11] Pincelli, C. and Yaar, M. (1997) Nerve Growth Factor: Its Significance in Cutaneous Biology. Journal of Investigative Dermatology Symposium Proceedings, 2, 61-68. https://doi.org/10.1038/jidsymp.1997.8

[12] Papoiu, A.D.P., Wang, H., Nattkemper, L., et al. (2011) A Study of Serum Concentrations and Dermal Levels of NGF in Atopic Dermatitis and Healthy Subjects. Neuropeptides, 45, 417-422. https://doi.org/10.1016/j.npep.2011.07.008

[13] Pugh, R., Murray Lyon, I., Dawson, J., Pietroni, M. and Williams, R. (1973) Transection of the Oesophagus for Bleeding Oesophageal Varices. British Journal of Surgery, 60, 646-649. https://doi.org/10.1002/bjs.1800600817

[14] Elman, S., Hynan, L., Gabriel, V. and Mayo, M. (2010) The 5-D Itch Scale: A New Measure of Pruritus. British Journal of Dermatology, 162, 587-593. https://doi.org/10.1111/j.1365-2133.2009.09586.x

[15] Lindor, K., Gershwin, M., Poupon, R., Kaplan, M. and Bergasa, N. (2009) Primary Biliary Cirrhosis. Hepatology, 50, 291-308. https://doi.org/10.1002/hep.22906

[16] Jones, D. (2012) Pathogenesis of Cholestatic Itch: Old Questions, New Answers and Future Opportunities. Hepatology, 56, 1194-1196. https://doi.org/10.1002/hep.25847

[17] Raap, U. and Kapp, A. (2005) Neuroimmunological Findings in Allergic Skin Diseases. Current Opinion in Allergy and Clinical Immunology, 5, 419-424. https://doi.org/10.1097/01.all.0000183111.78558.4d

[18] Michalak, A., Hanc, M., Fatyga, A. and Skublewska, A. (2011) Pruritus in Liver Disease-Pathogenesis and Treatment. Journal of Pre-Clinical and Clinical Research, 5, 47-49.

[19] Desphande, V., Burd, E., Aardema, K. and Moonka, D. (2001) High Levels of Hepatitis C Virus RNA in Native Livers Correlate with the Development of Cholestatic Hepatitis in Liver Allografts and a Poor Outcome. Liver Transplantation, 7, 118-124. https://doi.org/10.1053/jlts.2001.21278

[20] Zekri, A., Bahnassy, A., Mohamed, W., Alam El-Din, H. and Shousha, H. (2013) Dynamic Interplay between CXCL Levels in Chronic Hepatitis C Patients Treated by Interferon. Virology Journal, 10, 218. https://doi.org/10.1186/1743-422X-10-218 